\title{
Pivotal roles of protein 4.1B/DAL-1, a FERM-domain containing protein, in tumor progression (Review)
}

\author{
XIAOFENG YUAN $^{1 *}$, LIANHUA PIAO $^{2 *}$, LUHUI WANG $^{1}$, XU HAN $^{3}$, MING ZHUANG $^{1}$ and ZHIWEI LIU $^{1}$ \\ ${ }^{1}$ Department of Orthopaedics, The Third Affiliated Hospital of Soochow University, Changzhou, Jiangsu 213000; \\ ${ }^{2}$ Institute of Bioinformatics and Medical Engineering, Jiangsu University of Technology, Changzhou, Jiangsu 213001; \\ ${ }^{3}$ Department of Urology, The Third Affiliated Hospital of Soochow University, Changzhou, Jiangsu 213000, P.R. China
}

Received May 9, 2019; Accepted September 4, 2019

DOI: $10.3892 /$ ijo.2019.4877

\begin{abstract}
Protein 4.1B/DAL-1, encoded by erythrocyte membrane protein band 4.1-like 3 (EPB41L3), belongs to the protein 4.1 superfamily, a group of proteins that share a conserved four.one-ezrin-radixin-moesin (FERM) domain. Protein 4.1B/DAL-1 serves a crucial role in cytoskeletal organization and a number of processes through multiple interactions with membrane proteins via its FERM, spectrin-actin-binding and C-terminal domains. A number of studies have indicated that a loss of EPB41L3 expression is commonly observed in lung cancer, breast cancer, esophageal squamous cell carcinoma and meningiomas. DNA methylation and a loss of heterozygosity have been reported to contribute to the downregulation of EPB41L3. To date, the biological functions of protein 4.1B/DAL-1 in carcinogenesis remain unknown. The present review summarizes the current understanding of the role of protein $4.1 \mathrm{~B} / \mathrm{DAL}-1$ in cancer and highlights its potential as a cancer diagnostic and prognostic biomarker in cancer therapeutics.
\end{abstract}

\section{Contents}

1. Introduction

2. Structural characteristics of the protein 4.1 superfamily

3. Functional roles of individual domains of protein $4.1 \mathrm{~B} /$ DAL-1

4. Relevance of protein 4.1B/DAL-1 in cancer

5. Future directions

6. Conclusions

Correspondence to: Dr Zhiwei Liu, Department of Orthopaedics, The Third Affiliated Hospital of Soochow University, 185 Juqian Street, Changzhou, Jiangsu 213000, P.R. China

E-mail: liuzhiweil@126.com

*Contributed equally

Key words: protein 4.1B/DAL-1, erythrocyte membrane protein band 4.1-like 3, human carcinogenesis, therapeutic target

\section{Introduction}

Protein 4.1B/DAL-1 is encoded by erythrocyte membrane protein band 4.1-like 3 (EPB41L3; also termed DAL-1/ KIAA0987) and is important for cytoskeletal rearrangements, intracellular transport and signal transduction, with high levels of expression in the brain, intestine and kidney, and lower levels in the pancreas, lung and liver (1-4). Protein $4.1 \mathrm{~B} / \mathrm{DAL}-1$ belongs to the 4.1 protein superfamily, which is characterized by the presence of a highly conserved four.one-ezrin-radixin-moesin (FERM) domain at the $\mathrm{N}$-terminus (3-6). Compared with 4.1 superfamily members, 4.1B contains three conserved domains (FERM, SABD and CTD) and three unique domains (U1, U2 and U3) (7). DAL-1, a short form of $4.1 \mathrm{~B}$, is also located on human chromosome 18 p11.3 and lacks the U1, parts of the U2 and SABD, and full-length CTD (Fig. 1).

Protein 4.1B is a known tumor suppressor, and inactivation contributes to the progression and development of numerous cancer types, including lung adenocarcinoma (8-11), meningiomas (12-16), breast cancer $(17,18)$, ovarian cancer (19) and prostate cancer $(20,21)$. A loss of protein $4.1 \mathrm{~B}$ expression in cancer is partly associated with a loss of heterozygosity $(\mathrm{LOH})$ on $18 \mathrm{p} 11.3 \mathrm{and} / \mathrm{or}$ the hypermethylation of $\mathrm{CpG}$ islands (17). Protein $4.1 \mathrm{~B}$, a pivotal regulator of cytoskeletal structure, regulates various cytoskeletal-associated processes in cancer, including cell migration and invasion (22). Protein 4.1B has therefore received attention as a potential therapeutic target in cancer.

\section{Structural characteristics of the protein 4.1 superfamily}

Proteins isolated from human red blood cell membranes were first recognized as members of the protein 4.1 superfamily. Since their discovery, over 40 proteins have been demonstrated to belong to the protein 4.1 superfamily based on sequence homology $(3,23)$. In addition to the protein 4.1 subfamily, the protein 4.1 superfamily consists of four additional subfamilies: i) Talin-related molecules; ii) the ezrin, radixin, moesin protein family; iii) protein tyrosine phosphatases proteins; and iv) novel band 4.1-like 4 proteins (4). Members of the protein 4.1 superfamily possess diverse biological functions and share a highly conserved FERM domain of 200-300 amino acids, which is associated with the interaction with cytoplasmic domains of 
specific transmembrane proteins. In addition to the FERM domain, the protein 4.1 subfamily possesses two highly conserved spectrin-actin-binding (SAB) and C-terminal (CT) domains (7). The protein 4.1 family includes four homologues, 4.1R (erythrocyte-type), 4.1N (neuronal-type), 4.1G (general-type) and 4.1B (brain-type), which are encoded by EPB41, EPB41L1, EPB41L2 and EPB41L3, respectively (Fig. 2) (5,24).

\section{Functional roles of individual domains of protein 4.1B/DAL-1}

FERM domain. The FERM domain, first isolated from human erythrocyte ghosts, is a unique module in the family of peripheral membrane proteins that functions as a plasma membrane-cytoskeleton linker (6,25). Structurally, the FERM domain has a cloverleaf-like architecture with $\mathrm{N}$-lobes, $\alpha$-lobes and C-lobes (also termed F1, F2 and F3). The N-terminal FERM domain of $4.1 \mathrm{~B}$ has a number of interacting partners. For example, 4.1B binds via its FERM domain to the cytoplasmic domain of cell adhesion molecule (CADM)1/tumor suppressor in lung cancer 1 (TSLC1) $(11,26)$ and CADM4 (27). In addition, members of the membrane-associated guanylate kinase homologs, including membrane palmitoylated protein (MPP)1/p55, MPP2/discs large MAGUK scaffold protein 2 and MPP3, form a tripartite complex through their interaction with 4.1B and CADM1 (28). Protein arginine N-methyltransferase (PRMT)3 and PRMT5 also interact with 4.1B (29,30). The interactions between $4.1 \mathrm{~B}$ and contactin associated protein (CNTNAP)1 or CNTNAP2 serve essential roles in the organization of myelinated axons (31). The FERM domain of 4.1B also mediates binding to the 14-3-3 isoforms $\beta, \gamma$ and $\eta$ (32).

$S A B$ domain, CT domain and other unique domains. Protein 4.1B/DAL-1 maintains the mechanical integrity of cell membranes through its ability to form ternary complexes with spectrin and actin via its SAB domain (33). Functional variation exists amongst the different splice variants of SAB comprising of exons 16 and 17. Strong spectrin and actin binding affinity requires both exons, whilst exon 17 alone demonstrates weak affinity $(34,35)$. The SAB domain is also responsible for the interaction with sarcomeric proteins, such as myosin, $\alpha$-actin, and tropomyosin (36). The association between $4.1 \mathrm{~B}$ and $\alpha \mathrm{v} \beta 8$ integrin occurs via its CT domain (37). In addition to these domains, protein $4.1 \mathrm{~B}$ contains three unique regions (U1, U2 and U3). Membrane localization of the U2 domain, which is located between the FERM and SAB domains, is essential for 4.1B to function as a growth suppressor in meningioma (14). Collectively, protein $4.1 \mathrm{~B} / \mathrm{DAL}-1$ engages in a wide range of cellular functions through its interactions with dynamic molecules via its specific FERM, SAB and CT domains.

\section{Relevance of protein 4.1B/DAL-1 in cancer}

Aberrant protein 4.1B/DAL-1 expression occurs due to a $\mathrm{LOH}$ and/or DNA hypermethylation, and is implicated in numerous cancer types with a crucial role in tumor development and progression (Fig. 3).

Lung carcinoma. DAL-1, a short form of protein $4.1 \mathrm{~B}$ possessing all of its functional domains, was originally identified to be downregulated in primary lung tumors and lung cancer cell lines with a potential role in the suppression of tumor growth $(8,38,39)$. The hypermethylation of DAL-1 strongly correlates with a loss of DAL-1, and predicts a short overall survival in patients with NSCLC (9). In addition, EPB41L3 localizes within chromosomal region 18p11.3, which is influenced by a LOH in NSCLC (13). These studies indicate that both DNA methylation and $\mathrm{LOH}$ promote aberrant DAL-1 expression in NSCLC.

A noticeable feature of protein 4.1B/DAL-1 in lung cancer is its close association with epithelial-mesenchymal transition (EMT). It has been reported that protein 4.1B/DAL-1 maintains the phenotype of epithelial cells and attenuates EMT by inhibiting PI3K/Akt/Mdm2/p53 signaling as a result of the suppression of heat shock protein 5 in NSCLC $(40,41)$. A loss of protein $4.1 \mathrm{~B} / \mathrm{DAL}-1$ leads to a substantial decrease in the expression of numerous EMT markers, including E-cadherin and $\beta$-catenin in lung cancer cells (42). Additionally, through interaction with the tumor suppressor gene TSLC-1, an immunoglobulin superfamily cell-adhesion molecule possessing strong anti-tumor ability, protein 4.1B/DAL-1 regulates cell motility and actin rearrangements in cancer cells $(11,26,43)$.

Breast cancer. Human chromosomal region 18p11.3 frequently undergoes a LOH in breast cancer (18). However, despite significant LOH, the mutational mechanisms acting on the EPB41L3 locus are undefined. A significant allelic imbalance and preferential retention of the C-containing allele after $\mathrm{LOH}$ at this locus have been reported, indicating that loss of the T-containing alleles confers an advantage to the pathogenesis of breast cancer, providing clues to the mechanisms responsible for the loss of 4.1B in early breast cancer (17). Furthermore, promoter hypermethylation of EPB41L3 in intraoperative sentinel lymph node biopsy samples from patients with breast cancer is frequently observed and holds potential clinical utility (44).

Several studies have evaluated the role of $4.1 \mathrm{~B} / \mathrm{DAL}-1$ in breast cancer and have reported that its ability to modulate the activity of protein arginine methyltransferases PRMT3 and PRMT5 is via direct binding to the catalytic core domain of PRMTs in breast cancer cell lines $(29,30)$. Notably, protein 4.1B/DAL-1 can enhance and inhibit PRMT5 catalytic activity in a substrate-specific manner (29,30). Furthermore, protein 4.1B/DAL-1 and protein methylation mediated by protein arginine methyltransferases cooperate to induce apoptosis via a caspase-8-dependent pathway in MCF-7 breast cancer cells (45). These findings suggest that $4.1 \mathrm{~B} / \mathrm{DAL}-1$ influences breast cancer cell growth through the modulation of PRMT-dependent post-translational methylation.

Prostate cancer. Bisulfite sequencing and methylation-specific PCR revealed elevated levels of EPB41L3 hypermethylation in prostate cancer tissues and cell lines compared with the low methylation observed in normal prostate tissues (46-49). In particular, EPB41L3 expression increased through co-treatment with the DNA methyltransferase inhibitor (5-aza-2'-deoxycytidine) and a histone deacetylase inhibitor (SAHA) in Du145 and 22Rv1 prostate cancer cell lines, respectively (46). These studies illustrate that the loss of protein 4.1B/DAL-1 in prostate cancer is primarily associated with aberrant DNA methylation. Decreased expression of $4.1 \mathrm{~B}$ in highly metastatic prostate cancer cells 


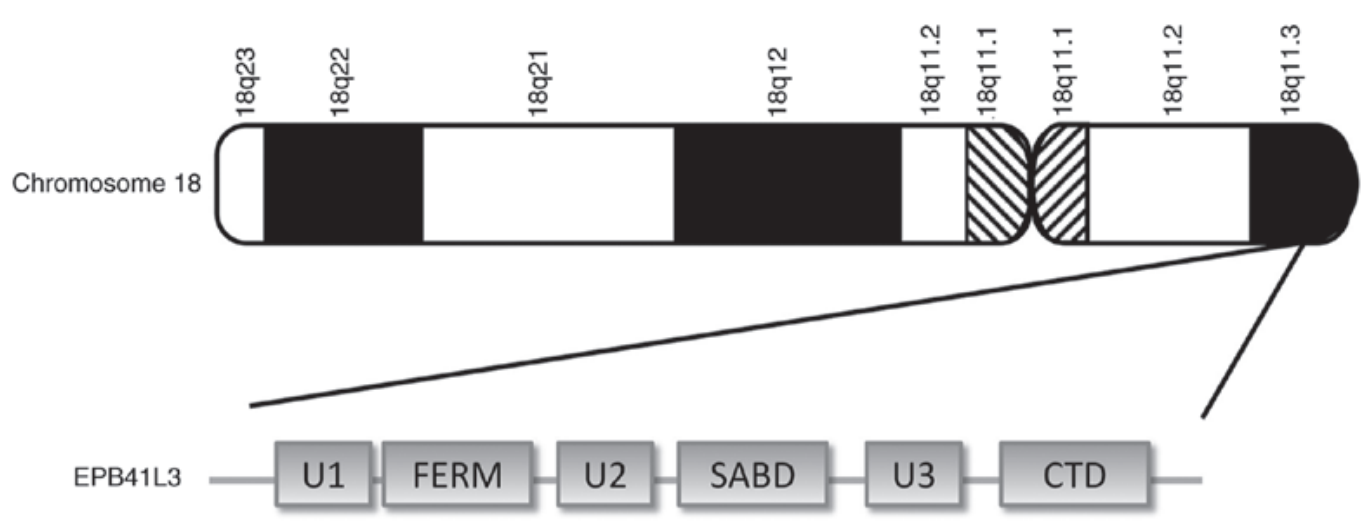

$\mathrm{N}$

$\mathrm{C}$

Protein 4.1B
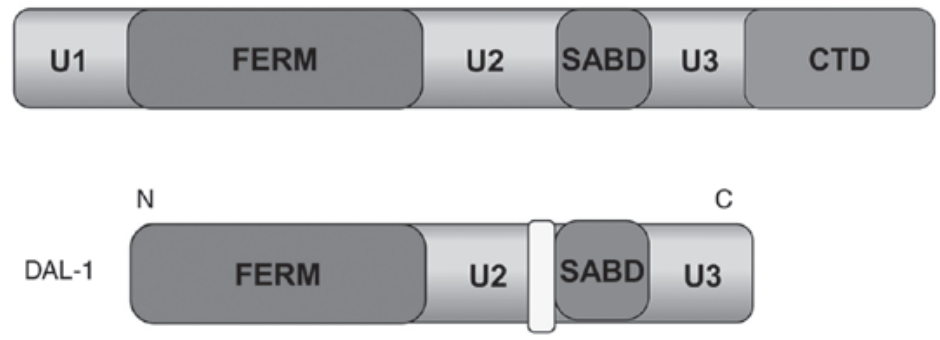

Figure 1. Gene localization of the EPB41L3 gene and domain structure of protein 4.1B/DAL-1. EPB41L3 is located on human chromosome 18p11.3. EPB41L3 possesses exons encoding FERM, SAB, CT, U1, U2 and U3 domains. The full-length protein encoded by EPB41L3 is termed protein 4.1B. DAL-1, a truncated form of protein 4.1B, which lacks N-terminal U1, parts of the U2 and SAB domains, and full-length C-terminal domain, is able to function as a tumor suppressor and inhibits cancer cell growth. EPB41L3, erythrocyte membrane protein band 4.1-like 3; FERM, four.one-ezrin-radixin-moesin; SAB, spectrin-actin-binding; CT, C-terminal.

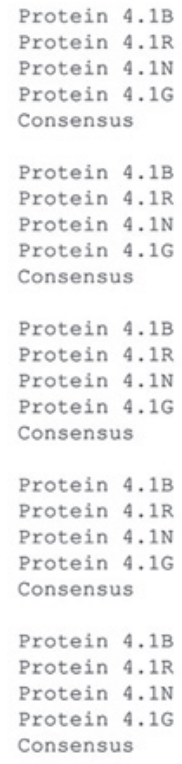

KPKSMQCKV̈ILLDGSEYTTCDVEKRRSRGQVL̈FDKVCEHLNL KHRNMHCKVSLLDDTVYECVVEKHAKGQDLLKRVCEHLNL KYKSAICRVTLLDASEYECEVEKHGRGQVLFDLVCEHLNI KYKSAICRVTLLDASEYECEVEKHGRGQVLFDLVCEHLNL KTKTVQCKVTLLDGTEYSCDLEKHAKGQVLFDKVCEHLNL
$\mathrm{k} \quad \mathrm{c}$ v $11 \mathrm{~d}$ y $\mathrm{c}$ ek gq 1 vceh1n1

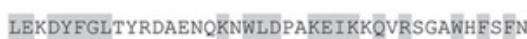
LEEDYEGLAIWDNTTSKTWLDSAKEIKKOVRGVPWNFTEN LEKDYFGLTFCDADSQKNWLDPSKEIKKQIRSSPWNFAFT le dyfgl $k$ wld keik q $r$ wf

\section{VKFYPPDPAQISEDITRYYLCLQLRDDIVSGRLPCSFVTIL} VKFYPPDPAQLTEDITRYYLCLQLRQDIVAGRLPCSFATL VKFYPPDPAQLTEDI TRYYLCLQLRADI ITGRLPCSFVTH VKFYPPDPSQLTEDITRYFLCLQLRQDIASGRLPCSFVTH vkfyppdp ql editry lclqlr di grlpcsf $t$

\section{ALLGSYTVQ̄SELGDYDPDECGSDYIS̄EFRFAPNHTKKELED} ALLGSYTIQSELGDYDPELHGVDYVSDFKLAPNOTKELEE ALLGSYAVQAELGDYDAEEHVGNYVSELRFAPNQTRELEE ALLGSYTLQAELGDYDPEEHGSIDLSEFQFAPTQTKELEE KVMELHKSYRSMTPAOADLEFLENAKKLSMYGVDLH RIMELHKTYRGMTPGEAEIHFLENAKKLSMYGVDLH KVAELHKTHRGLSPAQADSOFLENAKRLSMYGVDLH elhk $r$ a flenak lsmygudlh LEKDYFGLTFCDADSQKNWLDPSKEIKKQIRSSPWNEAT allgsy q elgdyd $s$ ap $t$ ele

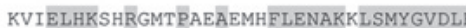

Figure 2. Sequence of the protein 4.1B N-terminal FERM domain aligned with other family members. Identical residues are highlighted in gray. FERM, four.one-ezrin-radixin-moesin.

indicates its role as a negative modulator of cancer progression and metastasis $(21,47)$. Notably, 4.1B-deficient mice demonstrate increased susceptibility for aggressive and spontaneous prostate tumors in transgenic adenocarcinoma of the mouse prostate tumor models (21). Based on these findings, reduced 4.1B expression appears an important event in prostate cancer that causally contributes to an aggressive tumor phenotype.
Esophageal squamous cell carcinoma (ESCC). Hypermethylated $\mathrm{CpG}$ sites in the promoter region of EPB41L3 lead to loss of expression and are identified in ESCC, which is consistent with studies in other cancer types (50). By contrast, it has been reported that EPB41L3 is significantly upregulated in ESCC compared with normal tissue. The enhanced expression of EPB41L3 is associated with the response to neoadjuvant chemoradiation in ESCC (51). Hence, further studies investigating the expression of EPB41L3 in ESCC are necessary to elucidate the full spectrum of its functions in EPB41L3.

Protein 4.1B/DAL-1 plays a significant role in suppressing cell migration and invasion via inhibiting matrix metalloproteinase (MMP)2 and MMP9 in ESCC (52). EPB41L3 positively regulates apoptosis through activating caspase-3/8/9, and inducing G2/M arrest via the CDK1 pathway (53). The specific functions of protein 4.1B/DAL-1 in the pathogenesis of ESCC are relatively uncharacterized and require further exploration.

Cervical cancer. The methylation of EPB41L3 can distinguish precancerous lesions from invasive disease in cervical specimens. High methylation of EPB41L3 in women with cervical intraepithelial neoplasia grade $2 / 3$ (CIN2/3) representing the pre-tumorigenic stage implies a higher cancer risk (54-57). Specifically, the methylation levels at $\mathrm{CpG}$ sites $(438,427$ and 425) in EPB41L3 may distinguish CIN2/3 from negative intraepithelial lesions or malignancy/CIN1 and cancer from CIN2/3 (58). Recent studies targeting women living with HIV-1 (WLHIV) in Burkina Faso and South Africa revealed that the hypermethylation of EPB41L3 is frequent among WLHIV and occurs in conjunction with low $\mathrm{CD}^{+}$counts and a poor efficacy of antiretroviral therapy (59). Indeed, when 

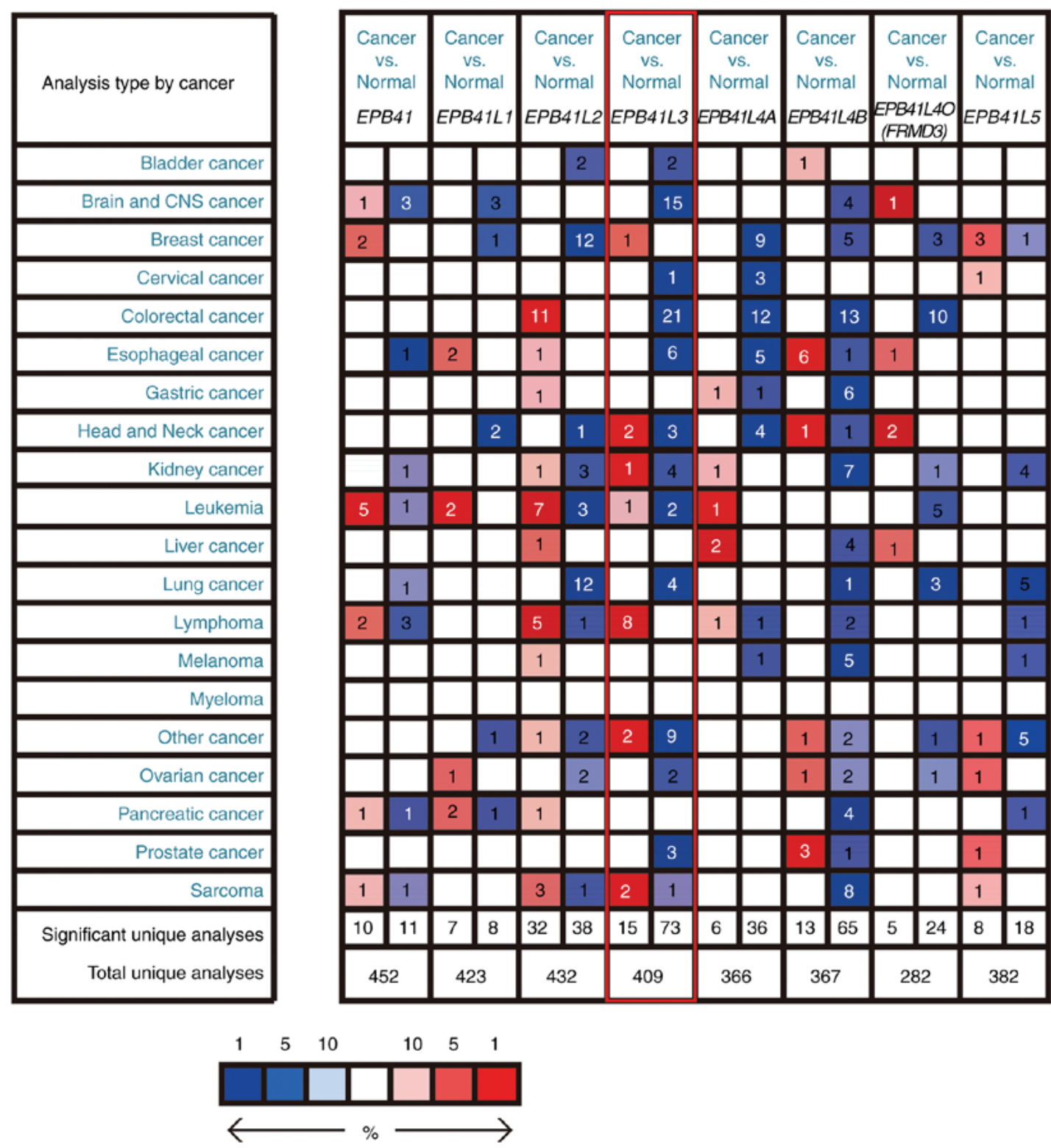

Cell color is determined by the best gene rank percentile for the analyses within the cell.

Figure 3. Transcription levels of EPB41L3 and other members of the 4.1 superfamily in different types of cancer. The data and figure are analyzed using the Oncomine database, indicating the numbers of datasets with statistically significant mRNA upregulation (red) or downregulation (blue). Different types of cancer vs. corresponding normal tissues. Threshold setting: P-value, 0.01 ; fold-change, 2; gene rank, top 10\%. The number in the colored cell represents the number of datasets meeting the threshold. EPB41L3, erythrocyte membrane protein band 4.1-like 3 .

screening for HPV infection, DNA methylation assessments of EPB41L3 offer promise as an objective molecular-based approach for early detection and diagnosis (60-69).

Meningiomas. A loss of protein 4.1B/DAL-1 occurs in $\geq 50 \%$ of the cases of sporadic meningiomas. As a major cause of downregulating EPB41L3, a LOH on chromosome segment $18 \mathrm{p} 11.3$ is common in meningiomas. However, meningioma with 18p11.3 LOH does not correlate with the nucleotide inactivation of EPB41L3 (12-14). EPB41L3 hypermethylation is a prognostic factor for poor survival in diffuse gliomas, and treatment with the demethylating agent 5-aza-2'-deoxycytidine and the histone deacetylase inhibitor trichostatin A have been shown to restore EPB41L3 expression in glioma cells (70). A loss of protein 4.1B/DAL-1 is reported as an early event in meningioma tumorigenesis, suggesting it plays a crucial role in growth regulation during meningioma pathogenesis (12). As a tumor suppressor, protein 4.1B/DAL-1 is associated with the activation of JNK in meningioma (16). Protein 4.1B/DAL-1 mediated growth suppression in meningioma requires the sequential activation of Src, Racl and JNK (16). Furthermore, the inhibition of Racl or JNK activation abrogates protein 4.1B-growth suppression. However, it is poorly understood how 4.1B/DAL-1 activates the JNK pathway.

Digestive system cancers. In addition to esophageal carcinoma, abnormal expression of EPB41L3 has been reported in other common digestive system cancer types, including gastric cancer, intestinal carcinoma, colorectal cancer, hepatocellular carcinoma and pancreatic carcinoma (71-75). Consistent with previous findings that Helicobacter pylori (HP)-induced 


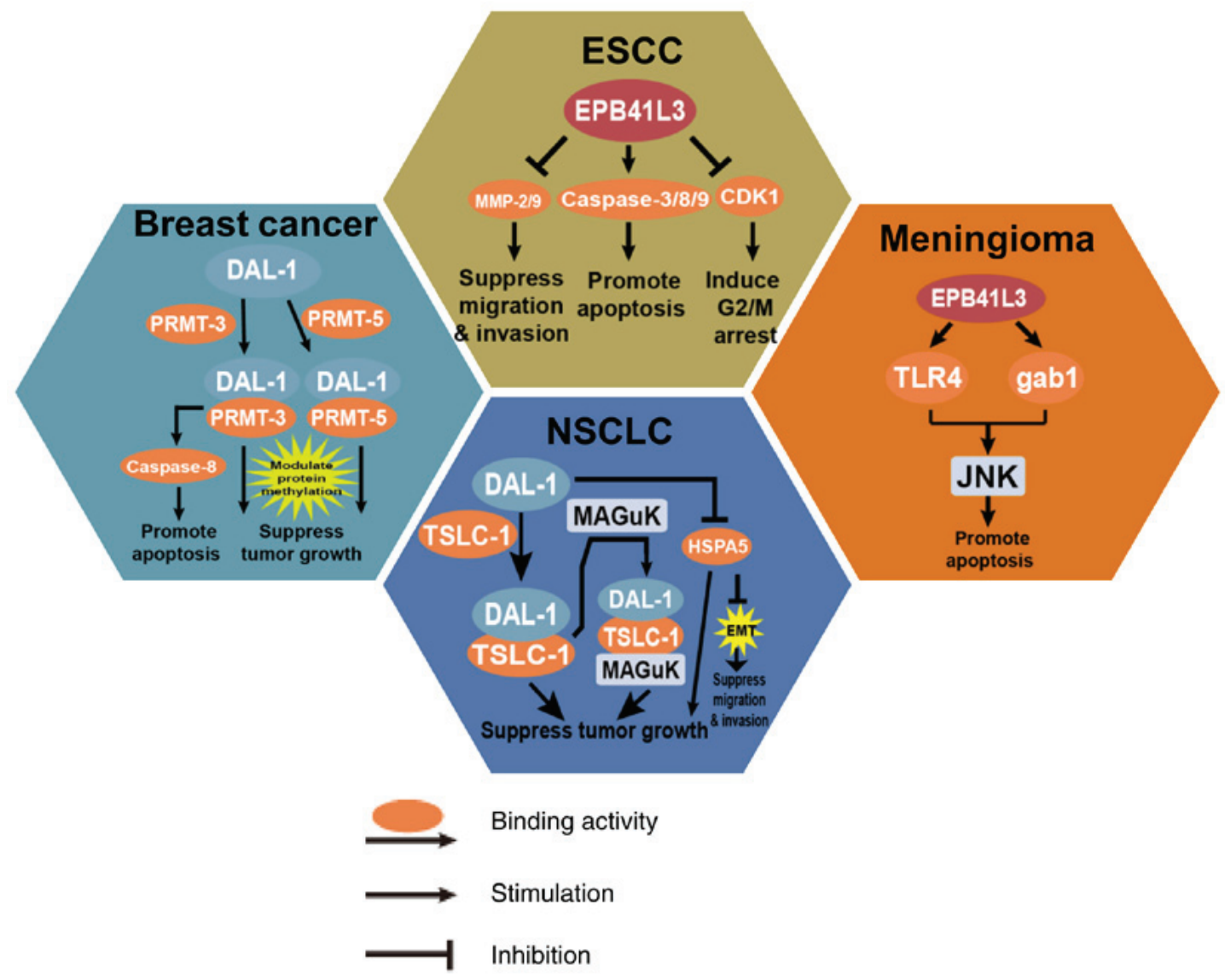

Figure 4. Multiple functions of EPB41L3 in several cancer including NSCLC, breast cancer, meningioma and ESCC. EPB41L3, erythrocyte membrane protein band 4.1-like 3; NSCLC, non-small cell lung cancer; ESCC, esophageal squamous cell carcinoma; TSLC-1, tumor suppressor in lung cancer 1; PRMT, protein arginine N-methyltransferase; HSPA5, heat shock $70 \mathrm{kDa}$ protein 5; MAGuK, membrane-associated guanylate kinase; MMP, matrix metalloproteinase; gab1, GRB2-associated binding protein 1; TLR4, toll-like receptor 4; EMT, epithelial-mesenchymal transition.

inflammatory response promotes EPB41L3 DNA methylation, the methylation of EPB41L3 is significantly lower in remnant gastric cancers with the decline of HP infection following distal gastrectomy $(73,74)$. In colorectal cancer, protein 4.1B/DAL-1 has been shown to be downregulated through membrane proteomic analysis (72). In addition, a similar loss of 4.1B/DAL-1 occurs in intestinal epithelia malignant carcinomas of mouse and humans (71). Protein 4.1B/DAL-1 is also downregulated in hepatocellular carcinoma (HCC), and represses HCC cell migration and invasion (76). Using transgenic mouse models of pancreatic b-cell carcinogenesis (Rip1Tag2), a loss of 4.1B has been reported in the phenotypic transition from adenoma to carcinoma (75). In addition, EPB41L3 and HPV 16 methylation are markedly higher amongst oropharyngeal cancer (OPC) with high sensitivity and specificity for the detection of OPC from an oral gargle, suggesting that measurements of HPV 16 and EPB41L3 methylation have utility in identifying early OPC (77). High methylation of EPB41L3 is also associated with anal intraepithelial neoplasia (78).

Renal cell carcinoma. Whilst protein 4.1B is expressed in the proximal uriniferous tubules of the normal human kidney, its loss or downregulation through EPB41L3 promoter hypermethylation occurs is $\sim 50 \%$ of renal clear cell carcinoma (RCCC) cases, implicating its association with EPB41L3 methylation, tumor grade and recurrence-free survival (79).
Furthermore, the protein 4.1B binding partner CADM4 serves an important role in the adhesion of the proximal uriniferous tubules that are the precursor cells of RCCC (27).

Other diseases. Similarly, promoter methylation of EPB41L3 is one of the common mechanisms of genetic downregulation in ovarian cancer (19). In addition, EPB41L3 is up-regulated with age and contributes to a decreased proliferation rate of human bone marrow-derived mesenchymal stem cells (80).

\section{Future directions}

Protein 4.1B/DAL-1 encoded by EPB41L3, functions as a tumor suppressor in human cancer $(5,22)$. The pathological functions of protein 4.1B/DAL-1 are versatile through its regulation of various cellular processes during carcinogenesis (Fig. 4). Nevertheless, the functions and mechanisms of EPB41L3 in cancer remain unknown.

Promoter methylation is a major cause of EPB41L3 inactivation in cancer. Abnormal DNA methylation of EPB41L3 is identified in numerous cancer types, including NSCLC and breast cancer $(9,44)$. Furthermore, aberrant EPB41L3 DNA methylation possesses high diagnostic and prognostic significance in cancer, indicating its potential use as a biomarker for cancer diagnosis (Table I). 
Table I. Potential use of EPB41L3 in different cancer types.

\begin{tabular}{|c|c|c|c|c|}
\hline Author, year & Cancer type & Status of EPB41L3 & $\begin{array}{l}\text { Potential use in } \\
\text { cancer therapy }\end{array}$ & (Refs.) \\
\hline Lorincz et al, 2017 & $\begin{array}{l}\text { Anal intraepithelial } \\
\text { neoplasia }\end{array}$ & DNA hypermethylation & Diagnostic significance & (78) \\
\hline Martín-Sánchez et al, 2016 & Breast cancer & DNA hypermethylation & Prognostic significance & (44) \\
\hline $\begin{array}{l}\text { Vasiljević et al, 2014; } \\
\text { Louvanto et al, 2015; } \\
\text { Nedjai et al, 2018; } \\
\text { Lorincz et al, 2016; } \\
\text { Eijsink et al, 2012; } \\
\text { Lendvai et al, 2012 }\end{array}$ & $\begin{array}{l}\text { Cervical intraepithelial } \\
\text { neoplasia and cancer }\end{array}$ & DNA hypermethylation & $\begin{array}{l}\text { Diagnostic and } \\
\text { significance prognostic }\end{array}$ & $\begin{array}{l}(55) \\
(58) \\
(63) \\
(66) \\
(68) \\
(69)\end{array}$ \\
\hline Kume et al, 2014 & Colorectal cancer & Low expression & Diagnostic significance & (72) \\
\hline Perez-Janices et al, 2015 & Diffuse gliomas & DNA hypermethylation & Prognostic significance & (70) \\
\hline $\begin{array}{l}\text { Li et al, 2014; } \\
\text { Zeng et al, } 2018\end{array}$ & $\begin{array}{l}\text { Esophageal squamous } \\
\text { cell carcinoma }\end{array}$ & DNA hypermethylation & $\begin{array}{l}\text { Diagnostic and prognostic } \\
\text { significance }\end{array}$ & $(50,53)$ \\
\hline Kikuchi et al, 2005 & $\begin{array}{l}\text { Non-small cell lung } \\
\text { cancer }\end{array}$ & DNA hypermethylation & Prognostic significance & (9) \\
\hline Giuliano et al, 2019 & Oropharyngeal cancer & DNA hypermethylation & Diagnostic significance & (77) \\
\hline $\begin{array}{l}\text { Vasiljević et al, 2014; } \\
\text { Schulz and Hoffmann, } \\
2009\end{array}$ & Prostate cancer & DNA hypermethylation & Diagnostic significance & $(48,49)$ \\
\hline Yamada et al, 2006 & $\begin{array}{l}\text { Renal clear cell } \\
\text { carcinoma }\end{array}$ & DNA hypermethylation & Prognostic significance & (79) \\
\hline
\end{tabular}

EPB41L3, erythrocyte membrane protein band 4.1-like 3.

Re-expression of EPB41L3 results in significant suppression of cell growth in ovarian cancer, lung cancer and breast cancer $(8,19,39)$. Particularly, reintroduction of EPB41L3 into 4.1B/DAL-1-null lung, breast and cervical cancer cell lines markedly suppresses cancer cell growth and promotes apoptosis $(8,39,64)$. Hence, EPB41L3 represents an attractive therapeutic strategy. Treatment with DNA methyltransferase inhibitors can restore the expression of EPB41L3 (81). Engineered artificial transcription factors can reactivate EPB41L3 with tumor suppressive roles in breast, ovarian and cervical cancer cell lines. Treatment of human amniotic fluid stem with CXCR4 promoters and adenovirus vector expressing DAL-1 permits the targeting of lung cancer xenografts that overexpress DAL-1, representing a strategy to restore EPB41L3 function (82). Such epigenetic reprogramming tools to reintroduce silenced tumor suppressor genes represent an emerging potential therapeutic strategy (64).

\section{Conclusions}

Protein 4.1B/DAL-1 is essential for cytoskeleton-associated processes by interacting with a series of protein molecules through its conserved FERM, SAB and CT domains. A loss of protein 4.1B/DAL-1 expression, caused by aberrant DNA methylation and/or $\mathrm{LOH}$, is frequently observed in cancer. Thus, protein 4.1B/DAL-1 can serve as a potential biomarker with high sensitivity and specificity for cancer diagnosis. In addition, reintroduction of protein 4.1B/DAL-1 by epigenetic inhibitors or genome-editing tools significantly inhibits tumor progression, indicating its potential as a novel promising target for cancer therapy. Taken together, growing evidence highlights the importance of protein 4.1B/DAL-1 in cancer progression, and further studies will be required to elucidate the regulatory mechanisms of protein $4.1 \mathrm{~B} / \mathrm{DAL}-1$ in human cancer.

\section{Acknowledgments}

Not applicable.

\section{Funding}

This research was supported by Changzhou Sci\&Tech Program (grant no. 20180170).

\section{Availability of data and materials}

Not applicable.

\section{Authors' contributions}

XY performed the original draft preparation. LP performed most of the revision work. XY and LP participated in the whole work. LW, XH and MZ contributed to figure preparation and revision, as well as editing of the manuscript. ZL provided financial support, edited the figures and contributed to editing 
of the manuscript. All authors read and approved the final manuscript.

\section{Ethics approval and consent to participate}

Not applicable.

\section{Patient consent for publication}

Not applicable.

\section{Competing interests}

The authors declare that they have no competing interests.

\section{References}

1. Cifuentes-Diaz C, Chareyre F, Garcia M, Devaux J, Carnaud M, Levasseur G, Niwa-Kawakita M, Harroch S, Girault JA, Giovannini $\mathrm{M}$ and Goutebroze L: Protein 4.1B contributes to the organization of peripheral myelinated axons. PLoS One 6: e25043, 2011.

2. Hoover KB and Bryant PJ: The genetics of the protein 4.1 family: Organizers of the membrane and cytoskeleton. Curr Opin Cell Biol 12: 229-234, 2000.

3. Diakowski W, Grzybek M and Sikorski AF: Protein 4.1, a component of the erythrocyte membrane skeleton and its related homologue proteins forming the protein 4.1/FERM superfamily. Folia Histochem Cytobiol 44: 231-248, 2006.

4. Takeuchi K, Kawashima A, Nagafuchi A and Tsukita S: Structural diversity of band 4.1 superfamily members. J Cell Sci 107: 1921-1928, 1994.

5. Sun CX, Robb VA and Gutmann DH: Protein 4.1 tumor suppressors: Getting a FERM grip on growth regulation. J Cell Sci 115: 3991-4000, 2002.

6. Chishti AH, Kim AC, Marfatia SM, Lutchman M, Hanspal M, Jindal H, Liu SC, Low PS, Rouleau GA, Mohandas N, et al: The FERM domain: A unique module involved in the linkage of cytoplasmic proteins to the membrane. Trends Biochem Sci 23: 281-282, 1998

7. Parra M, Gee S, Chan N, Ryaboy D, Dubchak I, Mohandas N, Gascard PD and Conboy JG: Differential domain evolution and complex RNA processing in a family of paralogous EPB41 (protein 4.1) genes facilitate expression of diverse tissue-specific isoforms. Genomics 84: 637-646, 2004.

8. Tran YK, Bögler O, Gorse KM, Wieland I, Green MR and Newsham IF: A novel member of the NF2/ERM/4.1 superfamily with growth suppressing properties in lung cancer. Cancer Res 59: 35-43, 1999.

9. Kikuchi S, Yamada D, Fukami T, Masuda M, Sakurai-Yageta M, Williams YN, Maruyama T, Asamura H, Matsuno Y, Onizuka M and Murakami Y: Promoter methylation of DAL-1/4.1B predicts poor prognosis in non-small cell lung cancer. Clin Cancer Res 11: 2954-2961, 2005.

10. Liang H, Yan X, Pan Y, Wang Y, Wang N, Li L, Liu Y, Chen X, Zhang CY, Gu H and Zen K: MicroRNA-223 delivered by platelet-derived microvesicles promotes lung cancer cell invasion via targeting tumor suppressor EPB41L3. Mol Cancer 14: 58, 2015.

11. Yageta M, Kuramochi M, Masuda M, Fukami T, Fukuhara H, Maruyama T, Shibuya M and Murakami Y: Direct association of TSLC1 and DAL-1, two distinct tumor suppressor proteins in lung cancer. Cancer Res 62: 5129-5133, 2002.

12. Gutmann DH, Donahoe J, Perry A, Lemke N, Gorse K, Kittiniyom K, Rempel SA, Gutierrez JA and Newsham IF: Loss of DAL-1, a protein 4.1-related tumor suppressor, is an important early event in the pathogenesis of meningiomas. Hum Mol Genet 9: 1495-1500, 2000.

13. Tran Y, Benbatoul K, Gorse K, Rempel S, Futreal A, Green M and Newsham I: Novel regions of allelic deletion on chromosome 18p in tumors of the lung, brain and breast. Oncogene 17: 3499-3505, 1998.

14. NunesF, Shen Y,Niida Y,BeauchampR,Stemmer-Rachamimov AO Ramesh V, Gusella $\mathbf{J}$ and MacCollin M: Inactivation patterns of NF2 and DAL-1/4.1B (EPB41L3) in sporadic meningioma. Cancer Genet Cytogenet 162: 135-139, 2005.
15. Robb VA, Gerber MA, Hart-Mahon EK and Gutmann DH: Membrane localization of the U2 domain of Protein 4.1B is necessary and sufficient for meningioma growth suppression. Oncogene 24: 1946-1957, 2005.

16. Gerber MA, Bahr SM and Gutmann DH: Protein 4.1B/differentially expressed in adenocarcinoma of the lung-1 functions as a growth suppressor in meningioma cells by activating Rac1-dependent c-Jun-NH(2)-kinase signaling. Cancer Res 66: 5295-5303, 2006

17. Kittiniyom K, Mastronardi M, Roemer M, Wells WA, Greenberg ER, Titus-Ernstoff L and Newsham IF: Allele-specific loss of heterozygosity at the DAL-1/4.1B (EPB41L3) tumor-suppressor gene locus in the absence of mutation. Genes Chromosomes Cancer 40: 190-203, 2004.

18. Kittiniyom K, Gorse KM, Dalbegue F, Lichy JH, Taubenberger JK and Newsham IF: Allelic loss on chromosome band 18p11.3 occurs early and reveals heterogeneity in breast cancer progression. Breast Cancer Res 3: 192-198, 2001.

19. Dafou D, Grun B, Sinclair J, Lawrenson K, Benjamin EC, Hogdall E, Kruger-Kjaer S, Christensen L, Sowter HM, Al-Attar A, et al: Microcell-mediated chromosome transfer identifies EPB41L3 as a functional suppressor of epithelial ovarian cancers. Neoplasia 12: 579-589, 2010.

20. Bernkopf DB and Williams ED: Potential role of EPB41L3 (protein 4.1B/Dal-1) as a target for treatment of advanced prostate cancer. Expert Opin Ther Targets 12: 845-853, 2008.

21. Wong SY, Haack H, Kissil JL, Barry M, Bronson RT, Shen SS, Whittaker CA, Crowley D and Hynes RO: Protein 4.1B suppresses prostate cancer progression and metastasis. Proc Natl Acad Sci USA 104: 12784-12789, 2007.

22. Wang Z, Zhang J, Ye M, Zhu M, Zhang B, Roy M, Liu J and An X: Tumor suppressor role of protein 4.1B/DAL-1. Cell Mol Life Sci 71: 4815-4830, 2014.

23. Holzwarth G, Yu J and Steck TL: Heterogeneity in the conformation of different protein fractions from the human erythrocyte membrane. J Supramol Struct 4: 161-168, 1976.

24. Parra M, Gascard P, Walensky LD, Gimm JA, Blackshaw S, Chan N, Takakuwa Y, Berger T, Lee G, Chasis JA, et al: Molecular and functional characterization of protein $4.1 \mathrm{~B}$, a novel member of the protein 4.1 family with high level, focal expression in brain. J Biol Chem 275: 3247-3255, 2000.

25. Leto TL and Marchesi VT: A structural model of human erythrocyte protein 4.1. J Biol Chem 259: 4603-4608, 1984.

26. Busam RD, Thorsell AG, Flores A, Hammarström M, Persson C, Öbrink B and Hallberg BM: Structural basis of tumor suppressor in lung cancer 1 (TSLC1) binding to differentially expressed in adenocarcinoma of the lung (DAL-1/4.1B). J Biol Chem 286: 4511-4516, 2011.

27. Nagata M, Sakurai-Yageta M, Yamada D, Goto A, Ito A, Fukuhara H, Kume H, Morikawa T, Fukayama M, Homma Y and Murakami Y: Aberrations of a cell adhesion molecule CADM4 in renal clear cell carcinoma. Int J Cancer 130: 1329-1337, 2012.

28. Sakurai-Yageta M, Masuda M, Tsuboi Y, Ito A and Murakami Y: Tumor suppressor CADM1 is involved in epithelial cell structure. Biochem Biophys Res Commun 390: 977-982, 2009.

29. Singh V, Miranda TB, Jiang W, Frankel A, Roemer ME, Robb VA, Gutmann DH, Herschman HR, Clarke S and Newsham IF: DAL-1/4.1B tumor suppressor interacts with protein arginine $\mathrm{N}$-methyltransferase 3 (PRMT3) and inhibits its ability to methylate substrates in vitro and in vivo. Oncogene 23: 7761-7771, 2004.

30. Jiang W, Roemer ME and Newsham IF: The tumor suppressor DAL-1/4.1B modulates protein arginine N-methyltransferase 5 activity in a substrate-specific manner. Biochem Biophys Res Commun 329: 522-530, 2005

31. Horresh I, Bar V, Kissil JL and Peles E: Organization of myelinated axons by Caspr and Caspr 2 requires the cytoskeletal adapter protein 4.1B. J Neurosci 30: 2480-2489, 2010.

32. Yu T, Robb VA, Singh V, Gutmann DH and Newsham IF: The 4.1/ezrin/radixin/moesin domain of the DAL-1/Protein 4.1B tumour suppressor interacts with 14-3-3 proteins. Biochem J 365: 783-789, 2002

33. Gimm JA, An X, Nunomura W and Mohandas N: Functional characterization of spectrin-actin-binding domains in 4.1 family of proteins. Biochemistry 41: 7275-7282, 2002.

34. Discher DE, Winardi R, Schischmanoff PO, Parra M, Conboy JG and Mohandas N: Mechanochemistry of protein 4.1's spectrin-actin-binding domain: Ternary complex interactions, membrane binding, network integration, structural strengthening. J Cell Biol 130: 897-907, 1995. 
35. Discher D, Parra M, Conboy JG and Mohandas N: Mechanochemistry of the alternatively spliced spectrin-actin binding domain in membrane skeletal protein 4.1. J Biol Chem 268: 7186-7195, 1993.

36. Kontrogianni-Konstantopoulos A, Huang SC and Benz EJ Jr: A nonerythroid isoform of protein $4.1 \mathrm{R}$ interacts with components of the contractile apparatus in skeletal myofibers. Mol Biol Cell 11: 3805-3817, 2000

37. McCarty JH, Cook AA and Hynes RO: An interaction between \{alpha\} $\mathbf{v}$ \{beta\} 8 integrin and Band $4.1 \mathrm{~B}$ via a highly conserved region of the Band 4.1 C-terminal domain. Proc Natl Acad Sci USA 102: 13479-13483, 2005.

38. Zhang Y, Xu R, Li G, Xie X, Long J and Wang H: Loss of expression of the differentially expressed in adenocarcinoma of the lung (DAL-1) protein is associated with metastasis of non-small cell lung carcinoma cells. Tumour Biol 33: 1915-1925, 2012.

39. Charboneau AL, Singh V, Yu T and Newsham IF: Suppression of growth and increased cellular attachment after expression of DAL-1 in MCF-7 breast cancer cells. Int J Cancer 100: 181-188, 2002.

40. Qiu X, Guan X, Liu W and Zhang Y: DAL-1 attenuates epithelial to mesenchymal transition and metastasis by suppressing HSPA5 expression in non-small cell lung cancer. Oncol Rep 38 : 3103-3113, 2017.

41. Chen X, Guan X, Zhang H, Xie X, Wang H, Long J, Cai T, Li S, Liu Z and Zhang Y: DAL-1 attenuates epithelial-to mesenchymal transition in lung cancer. J Exp Clin Cancer Res 34: 3, 2015.

42. Yu F, Yang H, Zhang Z, Wang Z and Xiong J: DAL-1/4.1B contributes to epithelial-mesenchymal transition via regulation of transforming growth factor- $\beta$ in lung cancer cell lines. Mol Med Rep 12: 6072-6078, 2015.

43. Heller G, Fong KM, Girard L, Seidl S, End-Pfützenreuter A Lang G, Gazdar AF, Minna JD, Zielinski CC and Zöchbauer-Müller S: Expression and methylation pattern of TSLC1 cascade genes in lung carcinomas. Oncogene 25: 959-968, 2006

44. Martín-Sánchez E, Pernaut-Leza E, Mendaza S, Cordoba A, Vicente-Garcia F, Monreal-Santesteban I, Vizcaino JP, De Cerio MJ, Perez-Janices N, Blanco-Luquin I, et al: Gene promoter hypermethylation is found in sentinel lymph nodes of breast cancer patients, in samples identified as positive by one-step nucleic acid amplification of cytokeratin 19 mRNA Virchows Arch 469: 51-59, 2016.

45. Jiang W and Newsham IF: The tumor suppressor DAL-1/4.1B and protein methylation cooperate in inducing apoptosis in MCF-7 breast cancer cells. Mol Cancer 5: 4, 2006.

46. Schulz WA, Alexa A, Jung V, Hader C, Hoffmann MJ, Yamanaka M, Fritzsche S, Wlazlinski A, Müller M, Lengauer T, et al: Factor interaction analysis for chromosome 8 and DNA methylation alterations highlights innate immune response suppression and cytoskeletal changes in prostate cancer. Mol Cancer 6: 14, 2007.

47. Schulz WA, Ingenwerth M, Djuidje CE, Hader C, Rahnenführer J and Engers R: Changes in cortical cytoskeletal and extracellular matrix gene expression in prostate cancer are related to oncogenic ERG deregulation. BMC Cancer 10: 505, 2010.

48. Vasiljević N, Ahmad AS, Carter PD, Fisher G, Berney DM Foster CS, Cuzick J and Lorincz AT: DNA methylation of PITX2 predicts poor survival in men with prostate cancer. Biomark Med 8: 1143-1150, 2014.

49. Schulz WA and Hoffmann MJ: Epigenetic mechanisms in the biology of prostate cancer. Semin Cancer Biol 19: 172-180, 2009

50. Li X, Zhou F, Jiang C, Wang Y, Lu Y, Yang F, Wang N, Yang H, Zheng Y and Zhang J: Identification of a DNA methylome profile of esophageal squamous cell carcinoma and potential plasma epigenetic biomarkers for early diagnosis. PLoS One 9: e103162, 2014.

51. Maher SG, Gillham CM, Duggan SP, Smyth PC, Miller N, Muldoon C, O'Byrne KJ, Sheils OM,HollywoodD and Reynolds JV: Gene expression analysis of diagnostic biopsies predicts pathological response to neoadjuvant chemoradiotherapy of esophageal cancer. Ann Surg 250: 729-737, 2009.

52. Zeng R, Huang JP, Li XF, Xiong WB, Wu G, Jiang ZJ, Song SJ, Li JQ, Zheng YF and Zhang JR: Epb4113 suppresses esophageal squamous cell carcinoma invasion and inhibits MMP2 and MMP9 expression. Cell Biochem Funct 34: 133-141, 2016.

53. Zeng R, Liu Y, Jiang ZJ, Huang JP, Wang Y, Li XF, Xiong WB, Wu XC, Zhang JR, Wang QE and Zheng YF: EPB41L3 is a potential tumor suppressor gene and prognostic indicator in esophageal squamous cell carcinoma. Int J Oncol: Mar 14, 2018 (Epub ahead of print)
54. Verlaat W, Van Leeuwen RW, Novianti PW, Schuuring E, Meijer CJLM, Van Der Zee AGJ, Snijders PJF, Heideman DAM, Steenbergen RDM and Wisman GBA: Host-cell DNA methylation patterns during high-risk HPV-induced carcinogenesis reveal a heterogeneous nature of cervical pre-cancer. Epigenetics 13: 769-778, 2018

55. Vasiljević N, Scibior-Bentkowska D, Brentnall AR, Cuzick J and Lorincz AT: Credentialing of DNA methylation assays for human genes as diagnostic biomarkers of cervical intraepithelial neoplasia in high-risk HPV positive women. Gynecol Oncol 132: 709-714, 2014.

56. Brentnall AR, Vasiljević N, Scibior-Bentkowska D, Cadman L, Austin J, Szarewski A, Cuzick J and Lorincz AT: A DNA methylation classifier of cervical precancer based on human papillomavirus and human genes. Int J Cancer 135: 1425-1432, 2014.

57. Boers A, Wang R, van Leeuwen RW, Klip HG, de Bock GH, Hollema $\mathrm{H}$, van Criekinge $\mathrm{W}$, de Meyer $\mathrm{T}$, Denil S, van der Zee AGJ, et al: Discovery of new methylation markers to improve screening for cervical intraepithelial neoplasia grade 2/3. Clin Epigenetics 8: 29, 2016

58. Louvanto K, Franco EL, Ramanakumar AV, Vasiljević N, Scibior-Bentkowska D, Koushik A, Cuzick J, Coutlée F and Lorincz AT; Biomarkers of Cervical Cancer Risk Study Team: Methylation of viral and host genes and severity of cervical lesions associated with human papillomavirus type 16. Int J Cancer 136: E638-E645, 2015.

59. Kelly HA, Chikandiwa A, Warman R, Segondy M, Sawadogo B, Vasiljević N, Didelot MN, Meda N, Weiss HA, Delany-Moretlwe S, et al: Associations of human gene EPB41L3 DNA methylation and cervical intraepithelial neoplasia in women living with HIV-1 in Africa. AIDS 32: 2227-2236, 2018.

60. Clarke MA, Luhn P, Gage JC, Bodelon C, Dunn ST, Walker J, Zuna R, Hewitt S, Killian JK, Yan L, et al: Discovery and validation of candidate host DNA methylation markers for detection of cervical precancer and cancer. Int J Cancer 141: 701-710, 2017.

61. Cuschieri K, Ronco G, Lorincz A, Smith L, Ogilvie G, Mirabello L, Carozzi F, Cubie H, Wentzensen N, Snijders P, et al: Eurogin roadmap 2017: Triage strategies for the management of HPV-positive women in cervical screening programs. Int J Cancer 143: 735-745, 2018.

62. Lorincz AT, Brentnall AR, Scibior-Bentkowska D, Reuter C, Banwait R, Cadman L, Austin J, Cuzick J and Vasiljević N: Validation of a DNA methylation HPV triage classifier in a screening sample. Int J Cancer 138: 2745-2751, 2016.

63. Nedjai B, Reuter C, Ahmad A, Banwait R, Warman R, Carton J, Boer S, Cuzick J and Lorincz AT: Molecular progression to cervical precancer, epigenetic switch or sequential model? Int J Cancer: Apr 21, 2018 (Epub ahead of print).

64. Huisman C, van der Wijst MG, Falahi F, Overkamp J, Karsten G, Terpstra MM, Kok K, van der Zee AG, Schuuring E, Wisman GB and Rots MG: Prolonged re-expression of the hypermethylated gene EPB41L3 using artificial transcription factors and epigenetic drugs. Epigenetics 10: 384-396, 2015.

65. Brentnall AR, Vasiljević N, Scibior-Bentkowska D, Cadman L, Austin J, Cuzick J and Lorincz AT: HPV33 DNA methylation measurement improves cervical pre-cancer risk estimation of an HPV16, HPV18, HPV31 and \extit\{EPB41L3\} methylation classifier. Cancer Biomark 15: 669-675, 2015.

66. Lorincz AT: Virtues and weaknesses of DNA methylation as a test for cervical cancer prevention. Acta Cytol 60: 501-512, 2016.

67. van Leeuwen RW, Ostrbenk A, Poljak M, van der Zee AGJ, Schuuring E and Wisman GBA: DNA methylation markers as a triage test for identification of cervical lesions in a high risk human papillomavirus positive screening cohort. Int J Cancer 144: 746-754, 2019.

68. Eijsink JJ, Lendvai Á, Deregowski V, Klip HG, Verpooten G, Dehaspe L, de Bock GH, Hollema H, van Criekinge W, Schuuring E, et al: A four-gene methylation marker panel as triage test in high-risk human papillomavirus positive patients. Int J Cancer 130: 1861-1869, 2012.

69. Lendvai Á, Johannes F, Grimm C, Eijsink JJ, Wardenaar R, Volders HH, Klip HG, Hollema H, Jansen RC, Schuuring E, et al: Genome-wide methylation profiling identifies hypermethylated biomarkers in high-grade cervical intraepithelial neoplasia. Epigenetics 7: 1268-1278, 2012.

70. Perez-Janices N, Blanco-Luquin I, Tuñón MT, Barba-Ramos E, Ibáñez B, Zazpe-Cenoz I, Martinez-Aguillo M, Hernandez B, Martínez-Lopez E, Fernández AF, et al: EPB41L3, TSP-1 and RASSF2 as new clinically relevant prognostic biomarkers in diffuse gliomas. Oncotarget 6: 368-380, 2015. 
71. Ohno N, Terada N, Murata S, Yamakawa H, Newsham IF, Katoh R, Ohara O and Ohno S: Immunolocalization of protein 4.1B/DAL-1 during neoplastic transformation of mouse and human intestinal epithelium. Histochem Cell Biol 122: 579-586, 2004.

72. Kume H, Muraoka S, Kuga T, Adachi J, Narumi R, Watanabe S, Kuwano M, Kodera Y, Matsushita K, Fukuoka J, et al: Discovery of colorectal cancer biomarker candidates by membrane proteomic analysis and subsequent verification using selected reaction monitoring (SRM) and tissue microarray (TMA) analysis. Mol Cell Proteomics 13: 1471-1484, 2014.

73. Niwa T, Tsukamoto T, Toyoda T, Mori A, Tanaka H, Maekita T, Ichinose M, Tatematsu M and Ushijima T: Inflammatory processes triggered by Helicobacter pylori infection cause aberrant DNA methylation in gastric epithelial cells. Cancer Res 70 : $1430-1440,2010$.

74. Sugimoto K, Ito T, Hulbert A, Chen C, Orita H, Maeda M, Moro H, Fukagawa T, Ushijima T, Katai H, et al: DNA methylation genome-wide analysis in remnant and primary gastric cancers. Gastric Cancer: Mar 12, 2019 doi: 10.1007/s10120-019-00949-5 (Epub ahead of print).

75. Terada N, Ohno N, Yamakawa H, Baba T, Fujii Y, Christofori G, Ohara $\mathrm{O}$ and Ohno $\mathrm{S}$ : Protein 4.1B in mouse islets of Langerhans and beta-cell tumorigenesis. Histochem Cell Biol 120: 277-283, 2003.

76. Zhu L, Yang N, Chen J, Zeng T, Yan S, Liu Y, Yu G, Chen Q, Du G, Pan W, et al: LINC00052 upregulates EPB41L3 to inhibit migration and invasion of hepatocellular carcinoma by binding miR-452-5p. Oncotarget 8: 63724-63737, 2017.
77. Giuliano AR, Nedjai B, Lorincz AT, Schell MJ, Rahman S, Banwait R, Boulware D, Sirak B, Martin-Gomez L, Abrahamsen M, et al: Methylation of HPV 16 and EPB41L3 in oral gargles: Associations with oropharyngeal cancer detection and tumor characteristics. Int J Cancer: Jul 15, 2019 (Epub ahead of print).

78. Lorincz AT, Nathan M, Reuter C, Warman R, Thaha MA, Sheaff M, Vasiljević N, Ahmad A, Cuzick J and Sasieni P: Methylation of HPV and a tumor suppressor gene reveals anal cancer and precursor lesions. Oncotarget 8: 50510-50520, 2017.

79. Yamada D, Kikuchi S, Williams YN, Sakurai-Yageta M, Masuda M, Maruyama T, Tomita K, Gutmann DH, Kakizoe T, Kitamura T, et al: Promoter hypermethylation of the potential tumor suppressor DAL-1/4.1B gene in renal clear cell carcinoma. Int J Cancer 118: 916-923, 2006.

80. Jiang SS, Chen CH, Tseng KY, Tsai FY, Wang MJ, Chang IS, Lin JL and Lin S: Gene expression profiling suggests a pathological role of human bone marrow-derived mesenchymal stem cells in aging-related skeletal diseases. Aging (Albany NY) 3: 672-684, 2011 .

81. Heller G, Geradts J, Ziegler B, Newsham I, Filipits M, Markis-Ritzinger EM, Kandioler D, Berger W, Stiglbauer W, Depisch D, et al: Downregulation of TSLC1 and DAL-1 expression occurs frequently in breast cancer. Breast Cancer Res Treat 103: 283-291, 2007.

82. Li L, Li S, Cai T, Wang H, Xie X, Liu Z and Zhang Y: The targeted inhibitory effects of human amniotic fluid stem cells carrying CXCR4 promoter and DAL-1 on non-small cell lung carcinoma growth. Gene Ther 23: 214-222, 2016. 